\title{
Giant Cell Tumor: A Rare Condition in the Immature Skeleton-A Retrospective Study of Symptoms, Treatment, and Outcome in 16 Children
}

\author{
Thale M. Asp Strøm, ${ }^{1}$ Anette Torød Skeie, ${ }^{2}$ Ingvild Koren Lobmaier, ${ }^{3}$ and Olga Zaikova ${ }^{1}$ \\ ${ }^{1}$ Department of Orthopedic Surgery, The Norwegian Radium Hospital, Oslo University Hospital, Oslo, Norway \\ ${ }^{2}$ Department of Radiology, The Norwegian Radium Hospital, Oslo University Hospital, Oslo, Norway \\ ${ }^{3}$ Department of Pathology, The Norwegian Radium Hospital, Oslo University Hospital, Oslo, Norway
}

Correspondence should be addressed to Thale M. Asp Strøm; b21562@ous-hf.no

Received 29 August 2016; Accepted 24 October 2016

Academic Editor: Ajay Puri

Copyright (C) 2016 Thale M. Asp Strøm et al. This is an open access article distributed under the Creative Commons Attribution License, which permits unrestricted use, distribution, and reproduction in any medium, provided the original work is properly cited.

\begin{abstract}
Background. Pediatric giant cell tumor (GCT) of bone is rare and the course of the disease in the immature skeleton is sparsely described. We performed a retrospective study addressing symptoms, treatment, and outcome in children with GCT. Methods. Review of medical records and images of patients with GCT. Patients were detected from our hospital prospective database and those with open epiphyseal cartilages were included. Results. 16 children (75\% girls) from 6 to 15 years old were identified. Eight lesions $(50 \%)$ were in long bones and $4(25 \%)$ in flat bones. One lesion appeared to be purely epiphyseal. All patients had pain as the initial symptom. Local recurrence developed in 2 patients. 14 of 16 patients returned to normal activity with no sequelae. One patient developed anisomelia after surgery. Conclusions. The biological tumor behavior in children does not seem to differ from what is reported in adults. Lesions in flat bones are very unusual, but our data alone do not provide enough evidence to conclude that this is more common in the immature skeleton. Literature review showed only one previous case report describing a purely epiphyseal GCT. Intralesional curettage is appropriate treatment and gives good functional results with acceptable recurrence rates.
\end{abstract}

\section{Introduction}

Giant cell tumor (GCT) of bone is one of the most common benign bone tumors accounting for $22 \%$ of benign bone tumors and $4-7 \%$ of all primary bone tumors $[1,2]$.

GCT is a benign but locally aggressive tumor and may even metastasize to the lungs. Rarely it presents as a malignant GCT.

Macroscopically the tumor tissue is soft, friable, and dark chocolate colored; however the color and consistency can vary greatly. Cystic portions may be present (Figure 1) and are sometimes so prominent that the lesion could be mistaken for an aneurysmal bone cyst (ABC) [2-4].

It is characterized microscopically by numerous multinucleated giant cells, which accounts for its name (Figures 2(a) and 2(b)). GCT typically presents as a lytic lesion in the epiphyseal/metaphyseal part of the long bones in an adult between 15 and 40 years of age, with peak incidence in the third decade of life $[1-3,5]$.

The gold standard for treating these tumors is surgery with intralesional curettage, the aim being local control without sacrificing function. Reported local recurrence rates vary between $14 \%$ and $25 \%$ in modern literature [6-8].

The lesion is exceptionally rare in children and, as a consequence, there is limited literature documenting the course of the disease in the immature skeleton. Picci et al. [9] presented a case series of 6 children from the Tumor Center in Bologna in 1983. Puri et al. [10] screened their database at Tata Memorial Hospital in Mumbai in 2007 and found 17 patients. These case series document the course of the disease compared with its adult form. Additional two articles from Schütte and Taconis in 1993 [11] and Kransdorf et al. in 1992 [12] describe GCT in younger patients, but mostly covering the radiological presentation. 


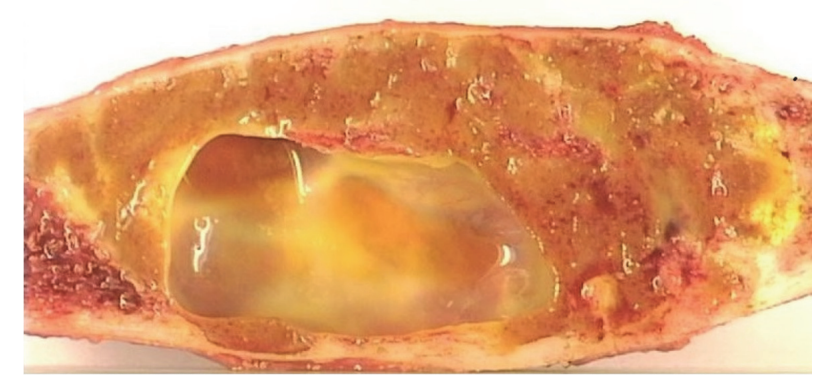

FIGURE 1: Giant cell tumor (GCT) in fibula with secondary aneurysmal bone cyst. Treated with wide resection.

To further our knowledge about this unusual subset of patients we performed a retrospective study addressing symptoms, treatment, and outcome in children with GCT of bone.

\section{Materials and Methods}

Patients with GCT of bone who were diagnosed and treated at our hospital between 1984 and 2015 were identified from our prospective database (Table 1). As skeletal immaturity can be difficult to ascertain without targeted radiographs with this in mind, we chose to include only patients under 16 years of age. We then excluded anyone among these who still appeared to have closed epiphyseal cartilages.

The patients' records were studied for clinical data, comorbidity, heredity, blood work, diagnostic method, pulmonary metastasis, multicentricity, operative methods, complications, and follow-up results.

A radiologist specialized in the field of musculoskeletal tumors (ATS) reviewed all the patients' radiological images.

A pathologist specialized in the field of mesenchymal tumors (IKL) reviewed the histological slides from all the lesions.

All included patients or their guardians have signed informed consent forms. The study has been approved by a personal data protection official at our institution.

\section{Results}

154 patients with GCT of bone treated at our hospital in the period 1984 to 2015 were detected. 137 (89\%) were older than 15 years at the time of diagnosis and were excluded. One girl of 15 had closed epiphyseal cartilages on her radiographs and was also excluded.

The study population consisted of 12 girls and 4 boys, that is, $75 \%$ female predominance. The age range of the included patients was 6 to 15 years.

Lesions around the knee were the most common (25\%) and there were 8 lesions in long tubular bones. One lesion seems to have been purely epiphyseal at the time of presentation and then progressed into the metaphysis with time (Figures 3(a) and 3(b)). Further patient and tumor characteristics are presented in Table 1.

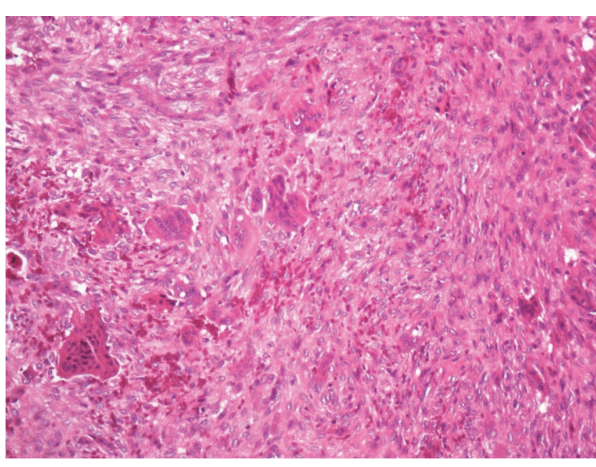

(a)

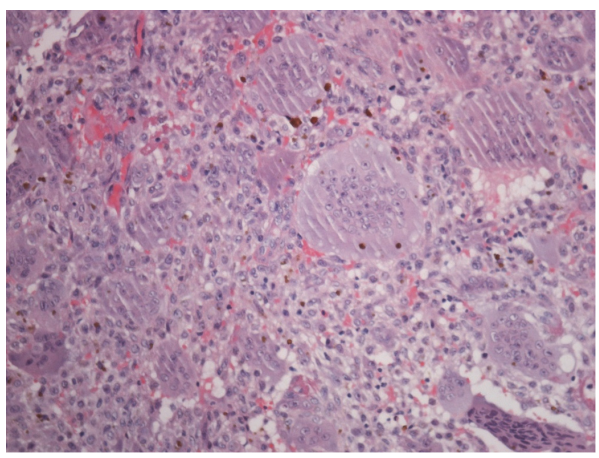

(b)

FIGURE 2: (a) Characteristic histology of giant cell tumor: mononuclear cells with round to oval nuclei interspersed with numerous multinucleated giant cells. (b) Larger magnification of a typical multinucleated giant cell.

All the patients presented with pain of varying degree. Some experienced pain only during activity. 12 of the patients also had swelling at the initial examination and 4 had reduced range of motion in the adjacent joint. One of the sacral lesions was associated with hip-pain, reduced muscle strength, and muscle atrophy in the ipsilateral lower extremity. Two had frank pathologic fractures and one had a hairline fracture. The duration of symptoms averaged 6 and 4 months (1-48).

Only one patient did not have a biopsy prior to surgery and this was because the lesion was largely cystic and did not present any tissue available for biopsy. The postoperative histology showed benign GCT in 13 of the lesions; 3 had benign GCT with a secondary ABC (Figure 1).

Histologically the tumors showed a variation of features within the normal histological appearance of giant cell tumors (Figures 2(a) and 2(b)): mononuclear cells with round to oval nuclei and eosinophilic, indistinct cytoplasm with some areas with spindle cell appearance. The giant cells had the same nuclear morphology and were partly evenly distributed throughout the tumor, partly in clusters.

Plain chest X-ray or chest CT were obtained of 15 of the 16 patients prior to surgery and there were none presenting with pulmonary metastasis.

One patient had multicentric GCT with two metachronous lesions, one in the proximal tibia and one in the cuneiform bone in the same extremity 15 years later. The 


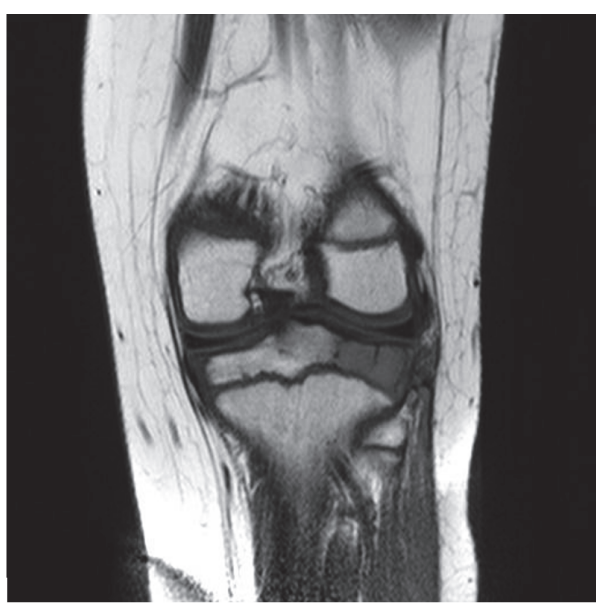

(a)

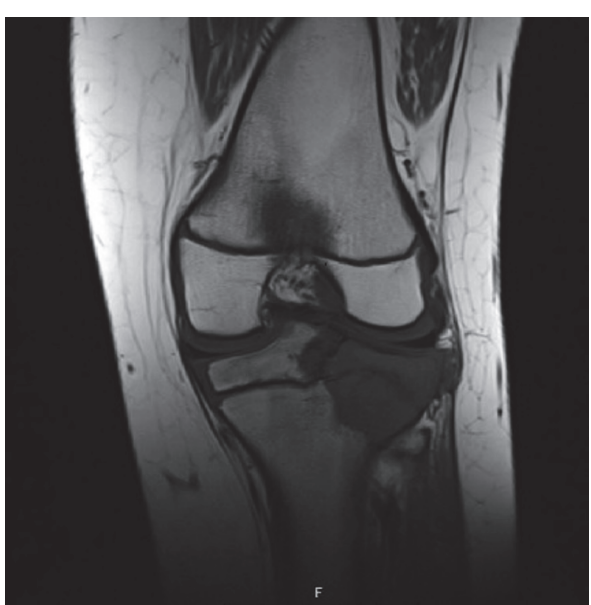

(b)

Figure 3: (a) MRI of a purely epiphyseal giant cell tumor in a proximal tibia. (b) 9 months later the lesion had progressed to include the metaphysis as well.

TABLE 1: Patient characteristics.

\begin{tabular}{|c|c|c|c|c|c|c|c|c|c|}
\hline & Sex & $\begin{array}{c}\text { Age at } \\
\text { diagnosis } \\
\text { (years) }\end{array}$ & $\begin{array}{l}\text { Symptom } \\
\text { duration } \\
\text { (months) }\end{array}$ & $\begin{array}{l}\text { Affected } \\
\text { bone }\end{array}$ & $\begin{array}{l}\text { Localization } \\
\text { in bone }\end{array}$ & $\begin{array}{c}\text { Type of } \\
\text { operation/reconstruction }\end{array}$ & Recurrence & $\begin{array}{l}\text { Multicentric } \\
\text { disease }\end{array}$ & $\begin{array}{l}\text { Follow- } \\
\text { up time } \\
\text { (months) }\end{array}$ \\
\hline Patient 1 & M & 14 & 1 & Tibia & P-MD & Curettage + cement & - & - & 119 \\
\hline Patient 2 & $\mathrm{~F}$ & 14 & 6 & Tibia & P-EM & Curettage + cement & - & + & 220 \\
\hline Patient 3 & $\mathrm{~F}$ & 12 & 48 & Fibula & P-MD & Excision & - & - & 50 \\
\hline Patient 4 & $\mathrm{~F}$ & 15 & 2 & Tibia & D-M & Curettage + cement & - & - & 48 \\
\hline Patient 5 & $\mathrm{~F}$ & 6 & 1 & Fibula & $\mathrm{D}-\mathrm{MD}$ & Curettage + cement & + & - & 81 \\
\hline Patient 6 & $\mathrm{~F}$ & 9 & 1 & Tibia & P-E & Curettage + cement & - & - & 72 \\
\hline Patient 7 & $\mathrm{~F}$ & 15 & 5 & Fibula & $\mathrm{D}-\mathrm{MD}$ & Curettage + autograft & - & - & 50 \\
\hline Patient 8 & M & 15 & 6 & Radius & D-EMD & Curettage + allograft & + & - & 35 \\
\hline Patient 9 & $\mathrm{~F}$ & 10 & 4 & Sacrum & $\mathrm{P}$ & Curettage + cement & - & - & 90 \\
\hline Patient 10 & $\mathrm{~F}$ & 4 & 2 & Clavicle & $\mathrm{P}$ & Curettage + cement & - & - & 52 \\
\hline Patient 11 & $\mathrm{M}$ & 6 & 2 & Clavicle & $\mathrm{D}$ & Curettage + cement & - & - & 59 \\
\hline Patient 12 & $\mathrm{~F}$ & 8 & 5 & Sacrum & $\mathrm{P}$ & Curettage & - & - & 47 \\
\hline Patient 13 & $\mathrm{~F}$ & 10 & 1 & Clavicle & $\mathrm{D}$ & Curettage + cement & - & - & 50 \\
\hline Patient 14 & $\mathrm{~F}$ & 8 & 12 & 3.metatarsal & & Curettage + allograft & - & - & 28 \\
\hline Patient 15 & $\mathrm{M}$ & 9 & 2 & Scapula & & Curettage & - & - & 19 \\
\hline Patient 16 & $\mathrm{~F}$ & 10 & 6 & 3.metatarsal & & Curettage & - & & 17 \\
\hline
\end{tabular}

Male (M), female (F), proximal (P), distal (D), epiphyseal (E), metaphyseal (M), and diaphyseal (D).

initial lesion was extensive and complicated by fractures before and after surgery. It was initially treated with curettage and cementing. The second lesion was treated with excision and arthrodesis with autograft.

All lesions except one were treated with intralesional curettage. In 5 of these 15 patients some form of adjuvant was used: phenol in 2, high-speed bur in 2, and Pulsavac (highpressure irrigation with $\mathrm{NaCl}$ ) in 1 . Further treatment details are described in Table 1.

The patients in this material have a follow-up period ranging from 17 to 240 months. 14 of 16 patients returned to normal preoperative level of activity with no sequelae at last follow-up. The patient with a sacral lesion associated with reduced strength and muscle atrophy preoperatively developed contracture of the Achilles tendon. The patient with an extensive proximal tibial lesion and multicentric disease has a varus knee with medial arthrosis as an adult. One of the metatarsal lesions ended up with a shorter 3.metatarsal bone, but unaffected function. One patient had a proximal tibial lesion that crossed the epiphyseal cartilage as a 9-year-old (Figures 3(a) and 3(b)). Consequently an epiphysiodesis of the remaining epiphyseal cartilage was done to prevent an angular deformity. The patient then developed a limb-length inequality which was treated with shortening 


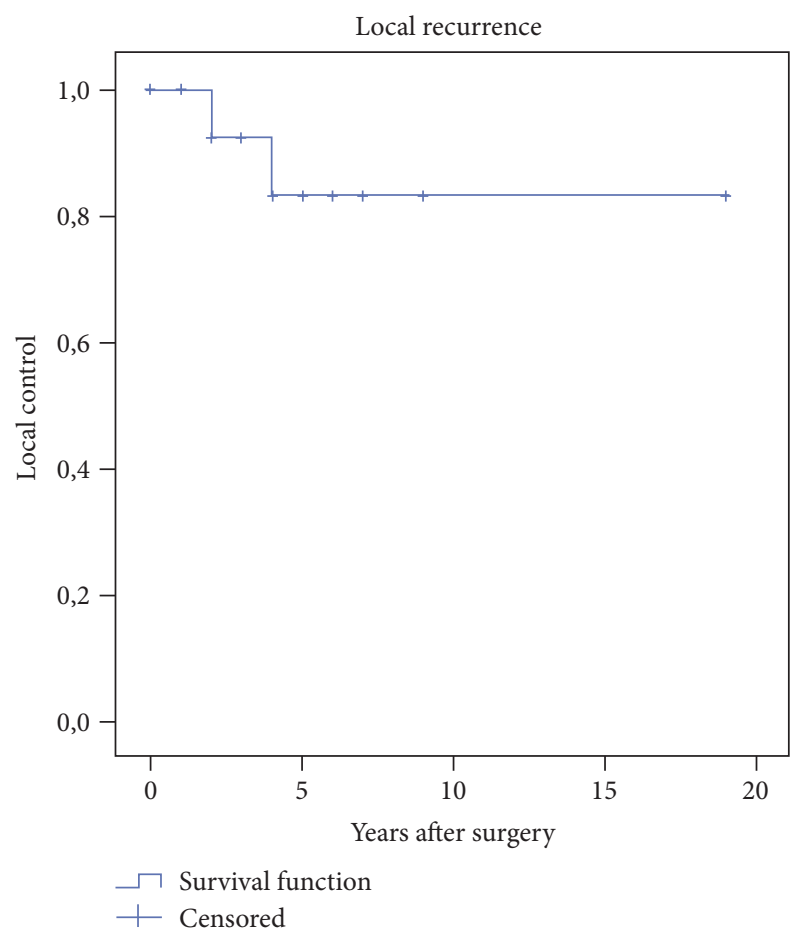

FIGURE 4: Kaplan-Meier cumulative survival curves for all patients under 16 years of age with giant cell tumor of bone (GCT) diagnosed and treated at our institution between 1984 and 2015.

osteotomies on the contralateral side. The patient had an unaffected function at last follow-up.

Local recurrence developed in 2 patients (Figure 4). One case in the distal fibula treated with curettage and cement initially developed a recurrence after 4 months. The other in the distal radius, treated with curettage and allograft initially, developed a recurrence after 14 months. Both reoperations were done with recurettage and cementing. They both remain disease-free at 8 and 2,5 years, respectively, after the initial surgery.

One of the patients with a sacral lesion had to have a reoperation less than 1 month after the initial surgery, but this was a complicated case in a difficult location around the S1 nerve root and it was regarded as residual tumor and not a local recurrence.

\section{Discussion}

Previously reported incidence of GCT in the immature skeleton varies between $0,5 \%$ and $10,6 \%[1,2,9-12]$. We showed an incidence of $10,4 \%$ of lesions in the immature skeleton from our total of 154 patients with GCT of bone in the selected period.

Some studies suggest a slight female predilection for GCT $[2,3,5]$, but others have found no difference between the genders [1,4]. Dahlin et al found 56\% females in the adult population with GCT in the Mayo Clinic files, but $72 \%$ in patients under 20 years of age [13]. Interestingly numerous publications have shown a larger female predominance (60$82 \%)$ in the younger age groups [9-11]. Kransdorf et al. [12] had $58 \%$ male patients, but they included patients up to 19 years of age.

In our material we had $75 \%$ girls in the group under 16 years and $72 \%$ if we considered patients up to 18 years of age. This seems in accordance with existing literature.

The anatomical region reported as most commonly affected is around the knee. $46-58 \%$ of the lesions occur here with the distal femur being the most frequent single location. Other fairly common locations are the distal radius, the proximal femur, the sacrum, and the proximal humerus. $90 \%$ are found in the long bones. The small bones of the hands and feet, the vertebrae, the pelvis, and the skull are rarely involved $[1-3,5]$.

Picci et al. [9] reported 6 children; all with lesions around the knee joint. Other publications regarding children report $22-53 \%$ of lesions occur around the knee [10-12]. Kransdorf et al. [12] found the majority (34\%) of lesions in the small bones of the hands and feet. It is now commonly accepted that GCT and "giant cell reparative granuloma/giant cell lesion of the small bones" are two distinct entities. The latter is more common in the first and second decades of life and are associated with a very good prognosis [2, 4, 14]. However Kransdorf et al. [12] state that in their opinion there is no cause for such a redefinition because the foci of fibrous proliferation and/or osseous differentiation may also be seen in GCT elsewhere in the skeleton. It is important to note that some authors on the other hand do not include giant cell reparative granulomas in their material on GCT. At our institution there was no prior tradition for differentiating between these two entities.

We report 5 lesions (29\%) around the knee which makes this the most common anatomical region in accordance with other publications. The 3 clavicular lesions and 1 in scapula are interesting as the flat bones are hardly ever affected. Puri et al. [10] found one clavicular lesion among the children in their material, and there are some existing case reports [15, 16]. Most of the larger materials contain none $[1-3,5]$. There is not enough evidence to conclude that this is more common in the immature skeleton from our small case series alone.

The localization within the bone is a point of special interest with regard to lesions in the immature skeleton. The typical GCT in an adult occurs at the end of a long bone with a metaphyseoepiphyseal location. The tumor very often extends to the subchondral bone or even to the articular cartilage and will in time often involve all/most of the epiphysis [2-4]. Lesions involving the metaphysis or the diaphysis without epiphyseal involvement are exceptionally rare. Historically the GCT was thought to occur in the epiphyseal part of the bone and then extend to the metaphysis $[3,13,17]$. However it became evident from isolated case reports and examples reported in larger series $[3,13,18]$ that purely metaphyseal lesions were more common in young patients, often before closure of the epiphyseal cartilage.

Campanacci et al. [1] found one diaphyseal and two metaphyseal lesions among 209 patients with GCT. They go on to say that cases with the tumor restricted exclusively to the epiphysis or apophysis were not known. They consequently advanced the hypothesis that GCT arise in the metaphysis and secondarily invade the epiphysis or apophysis. However, 
as early as 1952 Dr. Johnson, a pathologist in Washington, published a paper called "A General Theory of Bone Tumors" [19] where he looked at the functional and chemical kinship between different types of bone tumors. He stated that when the very small and presumably early tumors of each category are analyzed, it becomes apparent that there are preferential sites of origin within each bone. As an example he mentions GCTs, which when discovered while they are still small or before the epiphyseal plate closes are always located in the metaphysis.

Several studies have supported the view that a metaphyseal origin is likely. Rietveld et al. [17] looked at 233 cases in 1981 and found that the lesion could occasionally be shown to be restricted to the metaphysis; none were situated exclusively in an epiphysis. The materials published on young patients reinforce this view by showing a very high incidence of purely metaphyseal/predominantly metaphyseal lesions $[9,11,12$, 18]. The lesion is capable of crossing the epiphyseal cartilage [10], but epiphyseal involvement in young patients increases with increasing age [11].

Of our 8 lesions in long tubular bones, 7 involved the metaphysis and only 3 involved the epiphysis. We were surprised to find a lesion that appeared to be purely epiphyseal and then progressed to the metaphysis (Figures 3(a) and $3(\mathrm{~b})$ ). Only one previous case report describing a purely epiphyseal GCT was located after literature review so this is clearly unusual [20]. We do however have plain X-rays, CT scans, and MRI images of the early lesion and they all fail to show convincing metaphyseal involvement.

Our findings support a much higher incidence of metaphyseal or predominantly metaphyseal lesions in children.

Pain of variable degree is reported as the predominant symptom in the literature, at onset often only during activity and then more constant as the lesion progresses. More than three-quarters of patients have noted swelling of the affected region. Less common symptoms include weakness, limitation of adjacent joint motion, and pathologic fracture [2-4]. The clinical symptoms of the children in our study were no different from what is reported in the adult population.

Approximately $1 \%$ of patients with GCT have multiple synchronous or metachronous lesions. This has been shown to occur more frequently in younger patients [21]. One of our 16 children had multicentric GCT.

Pediatric GCTs have been treated in the same manner as in the adult patients, with curettage being the treatment of choice. We usually fill the cavity with cement, autograft, or banked allograft when the cavity is of some size and in a region which will be submitted to weight-bearing.

The Scandinavian Sarcoma Group Study from 2006 concluded that a local recurrence after curettage and cementing can generally be treated with further curettage and cementing with only a minor risk of increased morbidity, thus giving no incentive for more extensive and disabling surgery to avoid recurrence [8].

In modern literature the recurrence rate after curettage is $14-25 \%$ [6-8]. In younger patients it has been reported between $8 \%$ and $20 \%$ [9-11]. A local recurrence developed in 2 of 16 patients (13\%) in our cohort (Figure 4). However for 4 of the 16 patients the follow-up period was less than 4 years.
In spite of being a rare condition in the immature skeleton, GCT should be considered as a differential diagnosis in children with pain. The biological behavior of the tumor in children does not seem to differ significantly from what is reported in adults. Intralesional curettage is appropriate treatment and gives a good functional result with acceptable recurrence rate. $87 \%$ had no functional sequelae after surgery at the last follow-up, but one patient needed two additional surgical procedures to achieve a good functional result.

\section{Disclosure}

Level of evidence is Level IV, case series.

\section{Competing Interests}

The authors declare that there is no conflict of interests regarding the publication of this paper.

\section{Authors' Contributions}

Thale M. Asp Strøm collected and analyzed the data and prepared the manuscript. Anette Torød Skeie reviewed all the patients' radiological images. Ingvild Koren Lobmaier reviewed the histological slides from all the lesions. Olga Zaikova supervised the study.

\section{Acknowledgments}

The authors thank Trine Thoresen for her help with data collection and Heidi Buvarp Dyrop for advice and IT support. They are also grateful to Nils Jørgen Strøm and Joachim Thorkildsen for linguistic revision.

\section{References}

[1] M. Campanacci, A. Giunti, and R. Olmi, "Metaphyseal and diaphyseal localization of giant cell tumors," La Chirurgia Degli Organi di Movimento, vol. 62, no. 1, pp. 29-34, 1975.

[2] K. K. Unni and C. Y. Inwards, Dahlin's Bone Tumors: General Aspects and Data on 10,165 Cases, Lippincott Williams and Wilkins, 2010.

[3] R. R. Goldenberg, C. J. Campbell, and M. Bonfiglio, "Giant-cell tumor of bone. An analysis of two hundred and eighteen cases," The Journal of Bone \& Joint Surgery-American Volume, vol. 52, no. 4, pp. 619-664, 1970.

[4] R. E. Turcotte, "Giant cell tumor of bone," Orthopedic Clinics of North America, vol. 37, no. 1, pp. 35-51, 2006.

[5] H. L. Jaffe, Tumors and Tumorous Conditions of the Bones and Joints, Lea and Febiger, Philadelphia, Pa, USA, 1958.

[6] R. J. O’Donnell, D. S. Springfield, H. K. Motwani, J. E. Ready, M. C. Gebhardt, and H. J. Mankin, "Recurrence of giantcell tumors of the long bones after curettage and packing with cement," The Journal of Bone \& Joint Surgery-American Volume, vol. 76, no. 12, pp. 1827-1833, 1994.

[7] R. E. Turcotte, J. S. Wunder, M. H. Isler et al., "Giant cell tumor of long bone: a Canadian Sarcoma Group study," Clinical Orthopaedics and Related Research, no. 397, pp. 248-258, 2002. 
[8] F. Vult von Steyern, H. C. F. Bauer, C. Trovik et al., "Treatment of local recurrences of giant cell tumour in long bones after curettage and cementing. A Scandinavian Sarcoma Group study," The Journal of Bone and Joint Surgery. British Volume, vol. 88, no. 4, pp. 531-535, 2006.

[9] P. Picci, M. Manfrini, V. Zucchi et al., "Giant-cell tumor of bone in skeletally immature patients," The Journal of Bone \& Joint Surgery-American Volume, vol. 65, no. 4, pp. 486-490, 1983.

[10] A. Puri, M. G. Agarwal, M. Shah, N. A. Jambhekar, C. Anchan, and S. Behle, "Giant cell tumor of bone in children and adolescents," Journal of Pediatric Orthopaedics, vol. 27, no. 6, pp. 635-639, 2007.

[11] H. E. Schütte and W. K. Taconis, "Giant cell tumor in children and adolescents," Skeletal Radiology, vol. 22, no. 3, pp. 173-176, 1993.

[12] M. J. Kransdorf, D. E. Sweet, P. C. Buetow, M. A. I. Giudici, and R. P. Moser Jr., "Giant cell tumor in skeletally immature patients," Radiology, vol. 184, no. 1, pp. 233-237, 1992.

[13] D. C. Dahlin, R. E. Cupps, and E. W. Johnson Jr., "Giant-cell tumor: a study of 195 cases," Cancer, vol. 25, no. 5, pp. 1061-1070, 1970.

[14] C. D. M. Fletcher, J. A. Bridge, P. C. W. Hogendoorn, and F. Mertens, WHO Classification of Tumours of Soft Tissue and Bone, WHO Press, Lyon, France, 4th edition, 2013.

[15] S. Nagano, T. Tsuchimochi, M. Yokouchi et al., "Giant cell tumor of the clavicle: report of a case in a rare location with consideration of surgical method," BMC Musculoskeletal Disorders, vol. 16, article 142, 2015.

[16] V. Vaibhav, D. Kumar, and S. Singh, "Giant cell tumour of clavicle," Scientific Journal of Medical Science, vol. 3, no. 7, pp. 352-356, 2014.

[17] L. A. C. Rietveld, J. D. Mulder, G. Brutel de la Riviere, and T. G. van Rijssel, "Giant cell tumour: metaphyseal or epiphyseal origin?” Diagnostic Imaging, vol. 50, no. 6, pp. 289-293, 1981.

[18] J. S. Fain, K. K. Unni, J. W. Beabout, and M. G. Rock, "Nonepiphyseal giant cell tumor of the long bones. Clinical, radiologic, and pathologic study," Cancer, vol. 71, no. 11, pp. 3514-3519, 1993.

[19] L. C. Johnson, "A general theory of bone tumors," in The Bulletin New York Pathological Society, pp. 164-171, 1952.

[20] A. Gandhe, A. Sankhe, G. Aeron, and A. Joshi, "Epiphyseal giant cell tumour in an immature skeleton," The British Journal of Radiology, vol. 81, no. 963, pp. e75-e78, 2008.

[21] B. Hoch, C. Inwards, M. Sundaram, and A. E. Rosenberg, "Multicentric giant cell tumor of bone: clinicopathologic analysis of thirty cases," Journal of Bone and Joint Surgery-Series A, vol. 88, no. 9, pp. 1998-2008, 2006. 


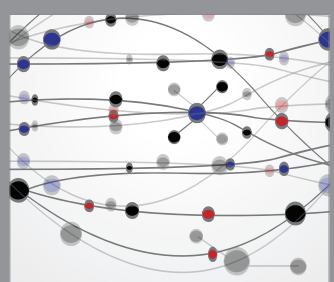

The Scientific World Journal
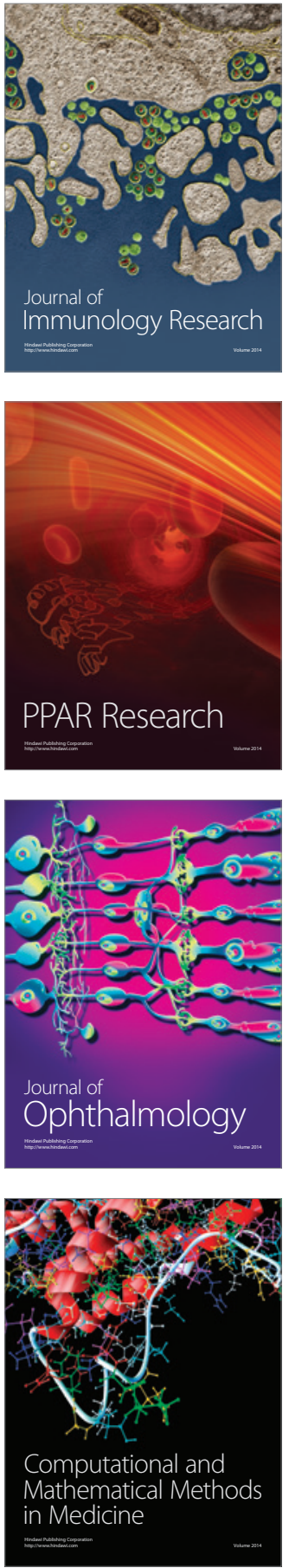

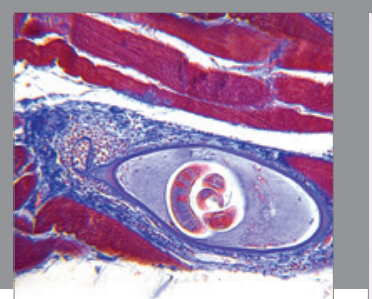

Gastroenterology Research and Practice

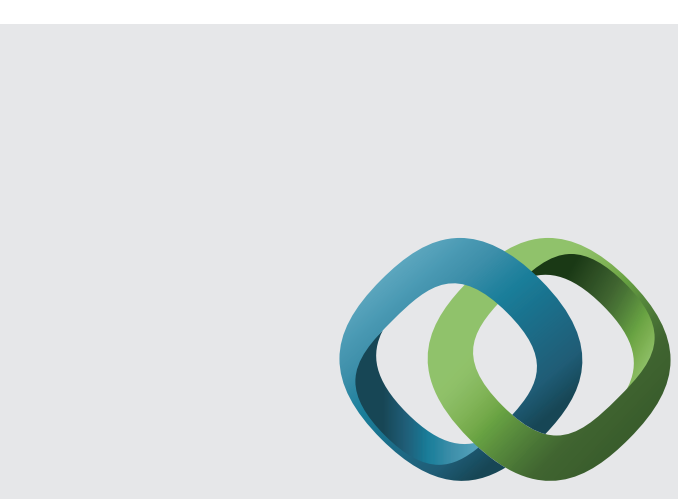

\section{Hindawi}

Submit your manuscripts at

http://www.hindawi.com
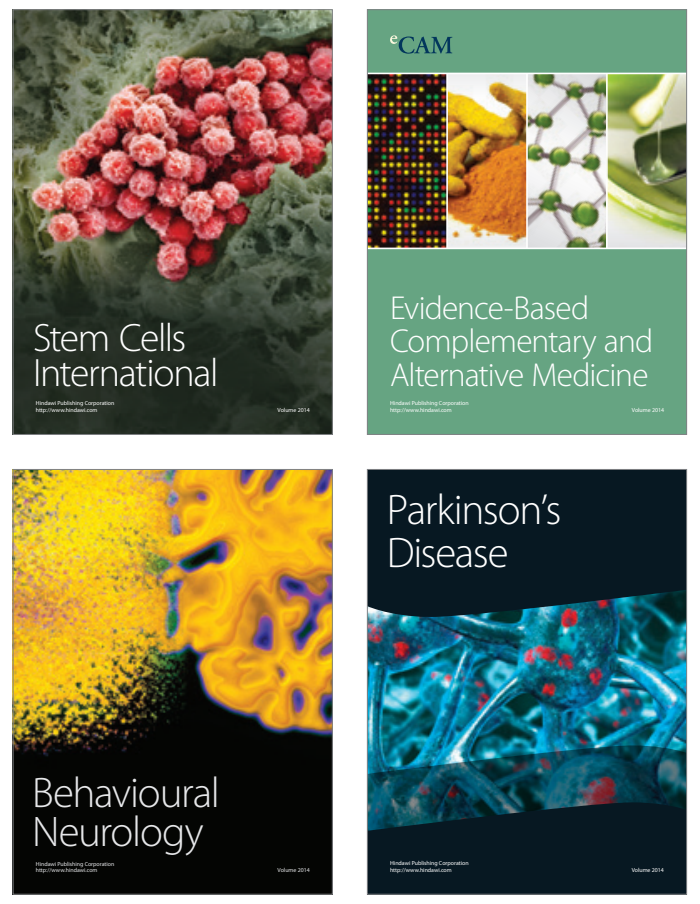
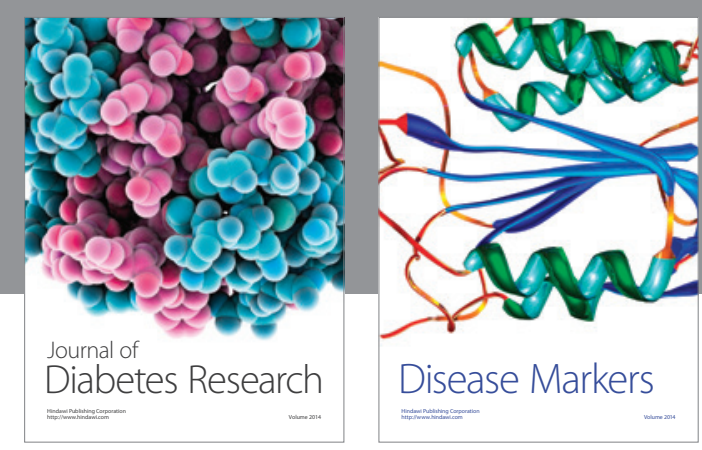

Disease Markers
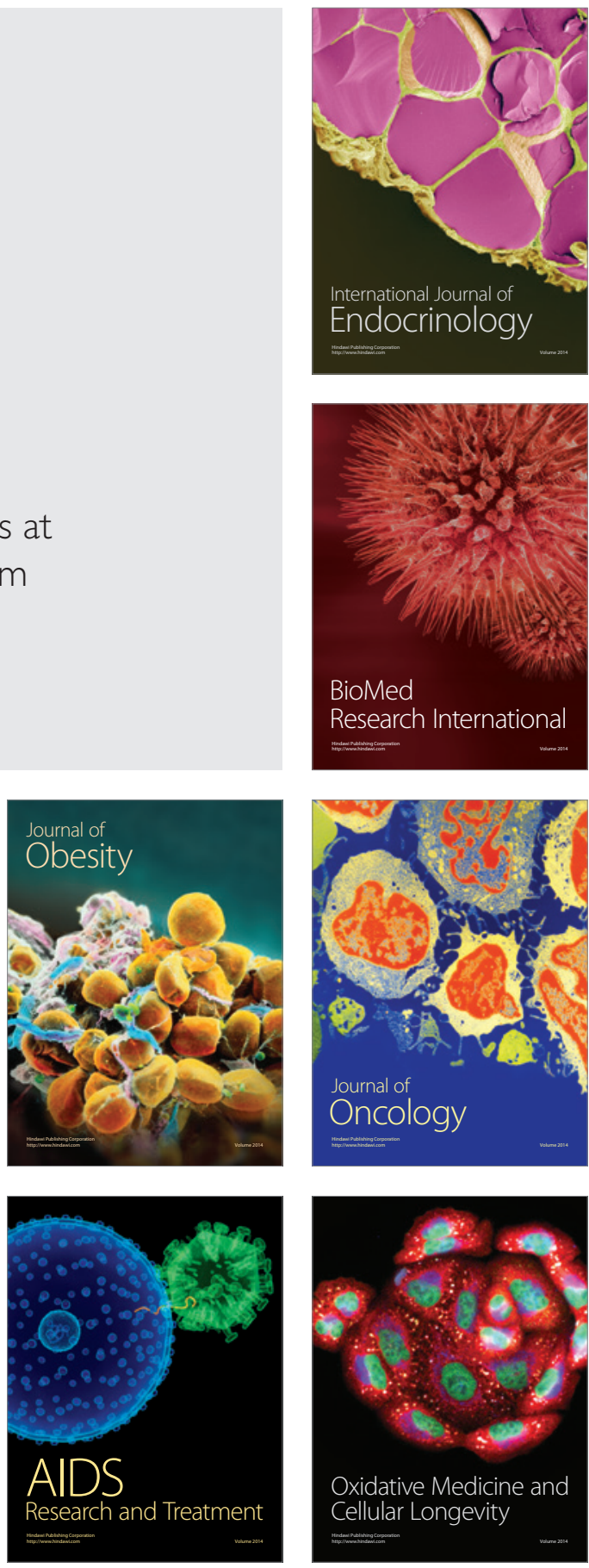